\title{
Designing the Controller of a Servo Valve by Simulation
}

\author{
Nicolae VASILIU*, Ina COSTIN, Constantin CĂLINOIU, \\ Daniela VASILIU, Marius D. BONTOS, \\ University POLITEHNICA of Bucharest, Fluid Power Laboratory, \\ 313 Splaiul Independentei, Sector 6, RO 060042 Bucharest, Romania \\ ina.i.costin@hotmail.com, calinoiu@fluid-power.pub.ro,daniela.vasiliu@upb.ro, bontosmarius@gmail.com, \\ *vasiliu1946@gmail.com (Corresponding author)
}

\begin{abstract}
The paper presents the research activities aiming to design the controller of a high flow electro-hydraulic servo valve needed for the power stage of the speed governors controlling high power hydraulic turbines operating under low oil pressure. This is the common case of any Kaplan turbine, but the refurbishing of the old Francis turbines needs the same valve configuration. Design problems, simulation methods and experimental researches are briefly presented. From an industrial point of view, the main idea of the new concept is the use of high-quality industrial electro-hydraulic and electronic components only, in order to obtain good performances even under a low-pressure supply. This target generated a new approach of the design by eliminating the pipes between the flow control stages. A detailed model of a high power servomechanism containing a three-stage non-linear electro hydraulic proportional servo valve was designed by simulation, taking into account the real geometry of the metering spool windows. The valve dynamic behaviour was simulated with SIMULINK and AMESIM, and finally the results were compared with some preliminary laboratory measurements. The simulated and the real responses for different inputs were found in good agreement.
\end{abstract}

Keywords: Simulation, controller fine-tuning, high power electro hydraulic servo valves, speed governors.

\section{Introduction}

Some important applications of the hydraulic control systems require very large flow, and special dynamic performance. A typical practical case can be found in the field of the earthquake simulators of the important buildings, fly simulation tables, automotive dynamics simulators etc. The variation of the speed and the power during the operation of a hydropower unit is achieved by adjusting the water flow that passes through the wicket gates. High accuracy electro hydraulic servo mechanisms actuate these control elements. The architecture of the power control system directly depends on hydropower unit size, specific speed, and the required dynamic performance. The last one depends on the quality requirements of the electrical power produced by the unit. The static and the dynamic forces that appear during the hydropower unit operation are rather large. The pistons of the hydraulic cylinders have rather large diameters, while the oil pressure is usually in the range 20-160 bar. The shut down time of a hydropower unit in case of a damage is usually lower than $10 \mathrm{~s}$. The current requirements regarding the quality of the electrical power provided by hydropower units are extremely strict, and meeting them requires speed governors to have a better accuracy than $2 \mathrm{mHz}$. This performance condition requires very precise positioning of the hydraulic cylinders rods, keeping a reasonable stability reserve for the speed governor. For medium size hydropower units, these contradictory requirements can be satisfied by means of a two-stage proportional flow servo valve (Figures 1 and 2), which has critical lap twoslope flow characteristics (Figure 3). Each metering land of the spool of such a flow control valve has rectangular slots (Figure 4). The servo valve dynamics (Figure 5) strongly depends on the supply pressure. The amplitude of the input signals is also an important parameter. A small supply pressure and a high

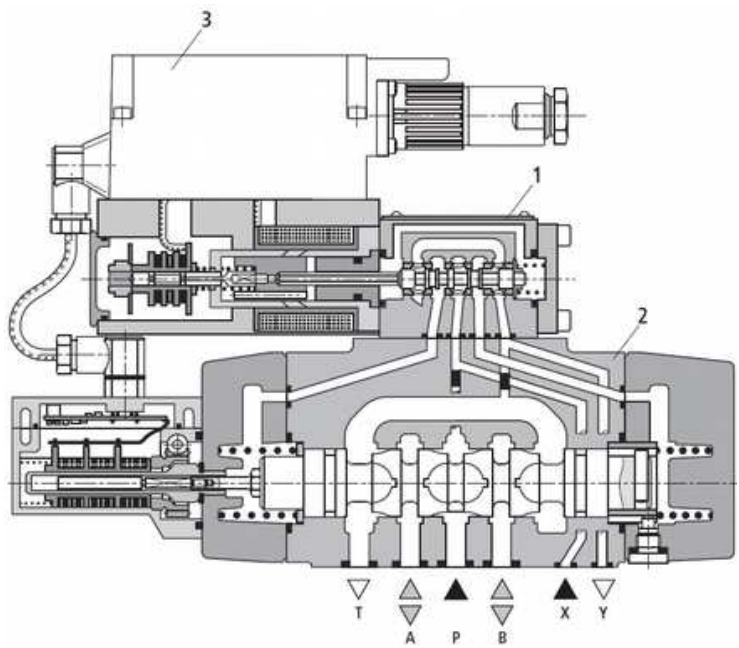

Figure 1. Two stage proportional flow servo valve 4WRLE 25 (REXROTH):

1-pilot; 2-power stage; 3-OBE 


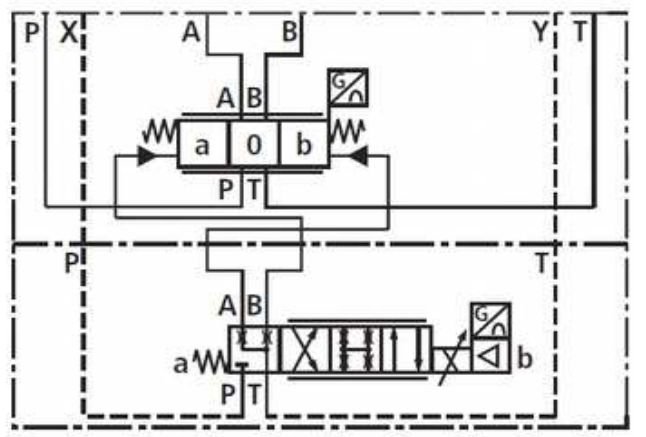

Figure 2. Hydraulic diagram of the two stages proportional servo valve

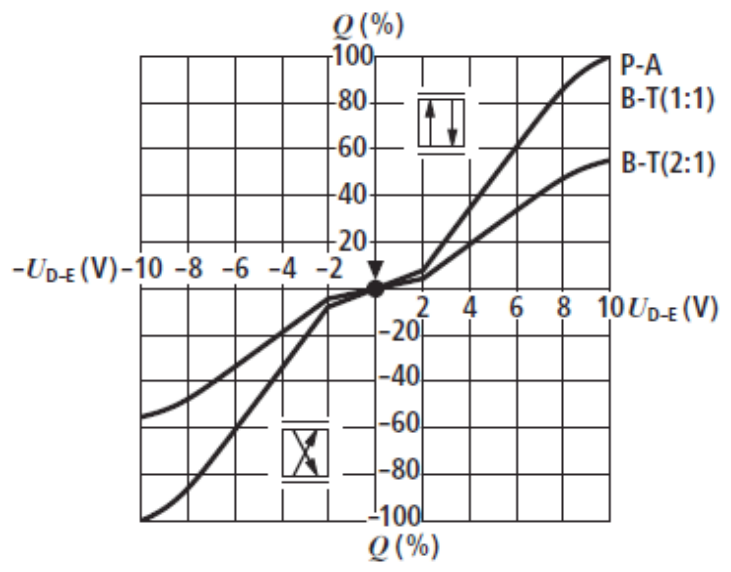

Figure 3. Flow characteristics of the two stage proportional servo valve 4WRLE 35

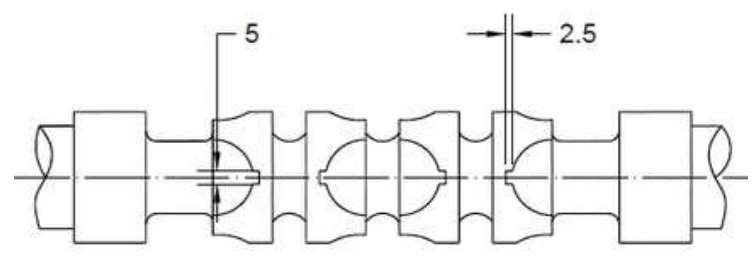

Figure 4. Typical spool with shaped metering windows

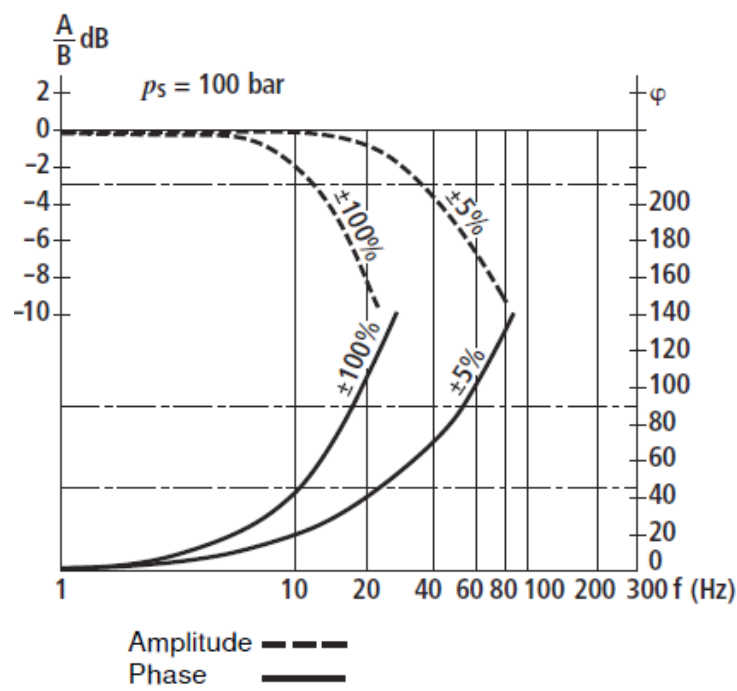

Figure 5. Typical dynamic performances of 4WRLE 25 proportional servo valves turbine nominal output lead to a three stages servo valve. For example, the two servomotors acting the wicket gates of the KAPLAN turbines of the IRON GATES I Hydropower Station from Danube River have a diameter of $600 \mathrm{~mm}$, and a stroke of $1,200 \mathrm{~mm}$. The servomotor stroking the runner blades has $3,120 \mathrm{~mm}$ diameter and a stroke of $300 \mathrm{~mm}$.

The pressure supply is about 40bar, and the emergency shutdown occurs in about 6 seconds. This performance requires a huge oil flow supplied by two control valves with three stages. The final stage is about $200 \mathrm{~mm}$ diameter. In such cases, the designer needs always a proper mathematical model and detailed simulations in order to optimize a complex architecture [1], [2], [3].

\section{New Hardware Design}

A proportional servo valve type 4WRLE 25 produced by REXROTH [11] was chosen to control a big diameter power stage. From security reasons, this stage was included in the fail-safe control loop of the governor, by means of a set of disc springs controlled by an external pressure supplied by the emergency shutdown section of the speed governor.

The power stage has a complex structure, which offers four flow control ways with a special design of the spool lands shown on Figure 4. Using a $100 \mathrm{~mm}$ spool diameter, the valve typical flow overcomes $7800 \mathrm{l} / \mathrm{min}$ under a very small pressure drop ( 5 bar on a metering edge). The flow of the hydraulic cylinders is normally controlled by the REXROTH servo valve. A sealed position transducer is measuring continuously the spool position, turning the whole assembly into a proportional device included in the position control loop of the wicket gates.

This new combination eliminates the pipes between the control stage and the power stage from the classical design. Such a way, the dynamic performances for the speed control are still very good, in spite of the very low supply pressure of the governor. An emergency signal generated by the speed governor creates in the third stage a wide connection needed to shut down the turbine in a few seconds.

However, an emergency directional flow valve is usually maintained in the hydraulic diagram of the speed governor, in parallel with the three 
stages servo valve, connected to the hydraulic servomotors. One end of the spool is always connected to the control oil supply system, and the other end can be quickly connected to the tank by a big cartridge valve controlled by a small two ways directional flow valve.

\section{New Controller Design}

The main problem raised by the use of an additional power stage is the stability of the whole valve. The previous research and studies carried out on the same problem by MTS System Corporation in the field of seismic platforms [5] revealed the need of a feed foreword lead term in the basic PI controller (Figure 6).

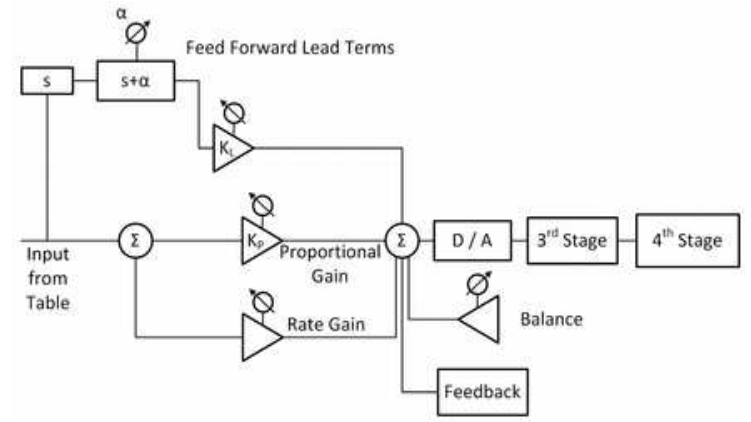

Figure 6. The MTS controller structure for four stages electro-hydraulic servo valve

The derivative component of the controller, with the input for the actuated seismic simulator table, offers good dynamic performance.

The only restriction of this servo valve is the very high level of the oil filtering system, because the first stage is a nozzle-flapper one. The recommended filtration level is about 3 microns absolute for the first stage, and about 10 microns absolute for the second stage (MTS 100-241-355 Specification).

In the case of a hydropower unit, the oil cleanness cannot be maintained at the above level. From this reason, the pilot stage of the new servo valve was chosen from the new family of the proportional high-speed servo valves, which uses one or a double solenoid for stroking a very light four way critical lap cylindrical spool.

All the attempts to change the available free design parameters of the third stage of the valve in order to avoid a strong instability pointed out the need of a filter $2 / 2$ on the spool position error. This is the same situation encountered in the synthesis of some fly control system of the big missile like Arianne [4]. It comes from the very small dumping factor of the third stage. A typical response to a step input of the filter is presented in Figure 7.

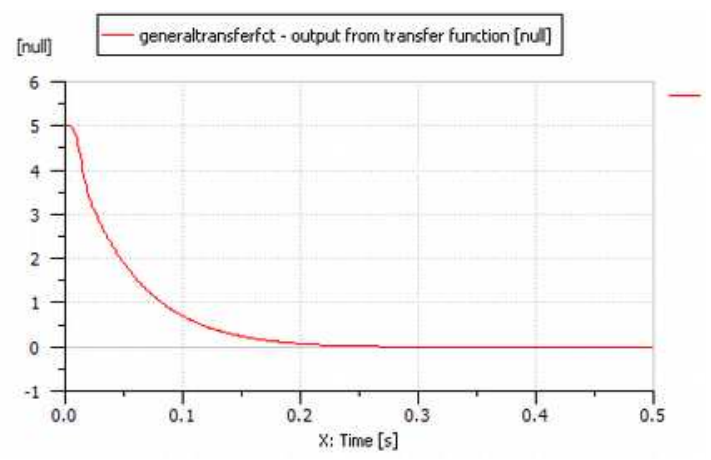

Figure 7. Step input response of the digital filter used on the error path

\section{Numerical Validation of the New Design}

AMESIM software [6], [7], [8] produced by LMS Company, a member of SIEMENS Group, was selected as a current simulation tool [9]. This complex software offers numerous advantages: rich library of hydraulic symbols and components, which allows the authors to use existing, proven models for wellknown components (valves, cylinders); ability to simulate different part of the system at different levels of complexity, which allows the authors to model different parts of the system at different levels of detail, as required.

AMESIM models are fully compatible with LabVIEW for real time and Hardware-in-theLoop simulations, can be imported in LabVIEW and connected to a real-time or HIL simulation system.

The power stage of the flow valve, which has the greatest influence on the dynamic behaviour of the system, was modelled in deep detail [10] at the physical process level, using the Hydraulic Component library of AMESIM in order to obtain access to all the internal variables.

The pilot stage, the cylinders, the pressure source etc. have been modelled at a more concise level, using predesigned blocks from the AMESIM Hydraulic and Mechanical libraries. Ultimately, the filter needed to improve the valve stability has been modelled by a transfer function, because the internal variables are not particularly important for the 
current simulation. The simplest AMESIM model developed by the authors for the three stages servo valve can be seen in Figure 8.

Many types of simulation have been performed using this model. First, the authors have simulated a step input signal in order to find the dynamics of each stage of the valve. The evolution of the main parameters of the system for the first simulation run are presented in Figures 9 - 14.

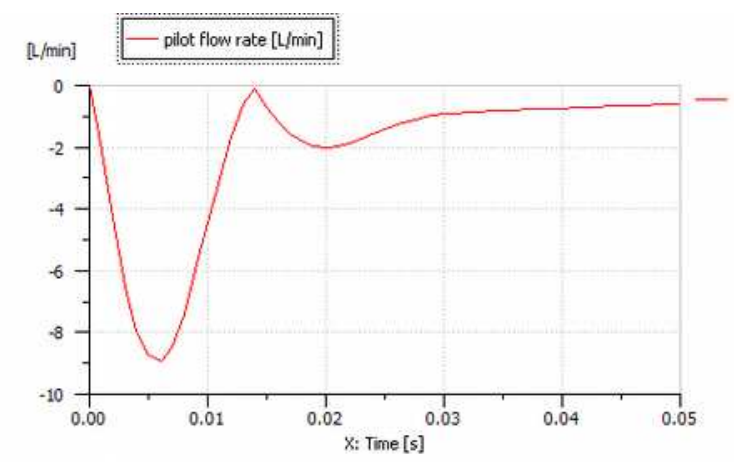

Figure 9. The flow rate of pilot the stage

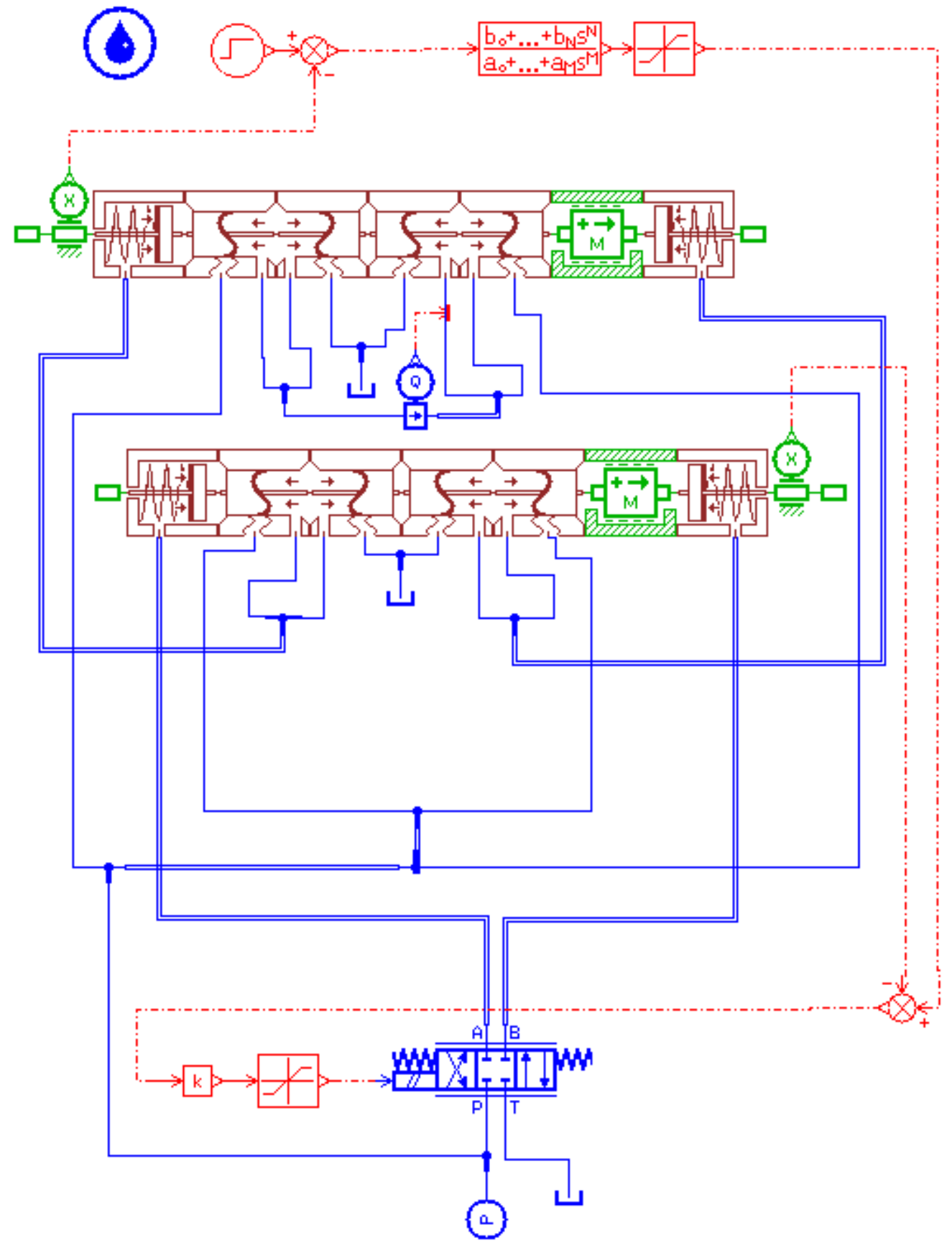

Figure 8. AMESIM simulation network for the three stages servo valve 


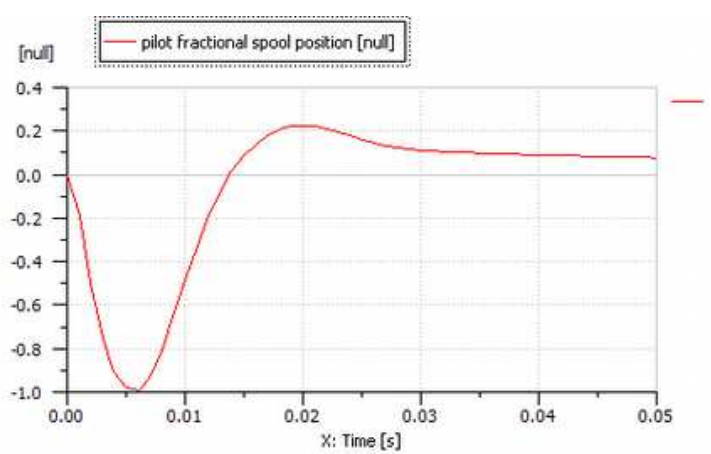

Figure 10. The first stage spool evolution

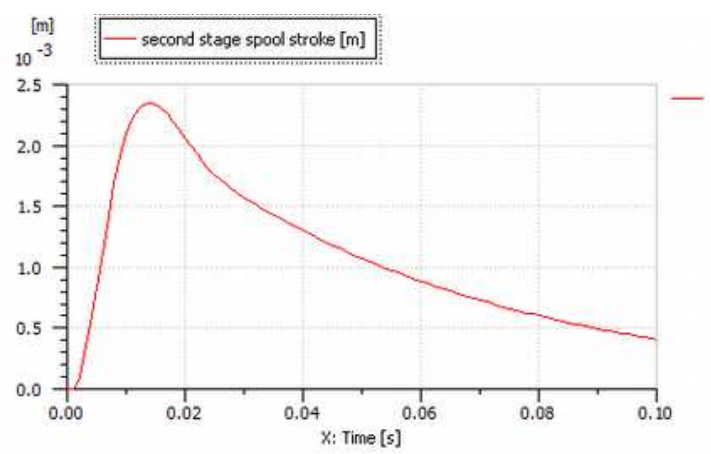

Figure 11. The second stage spool stroke

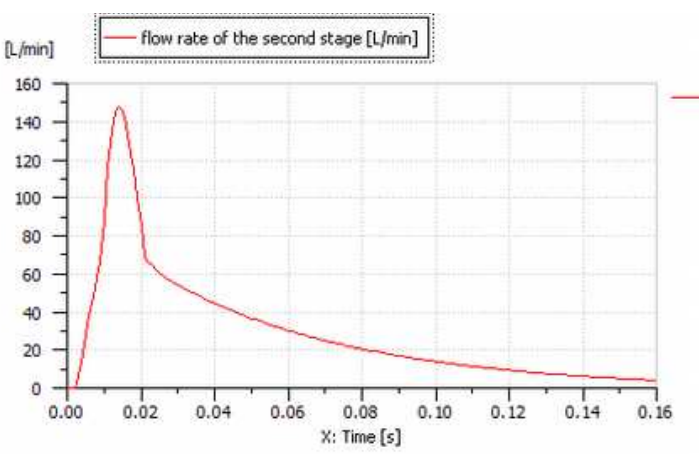

Figure 12. The second stage flow evolution

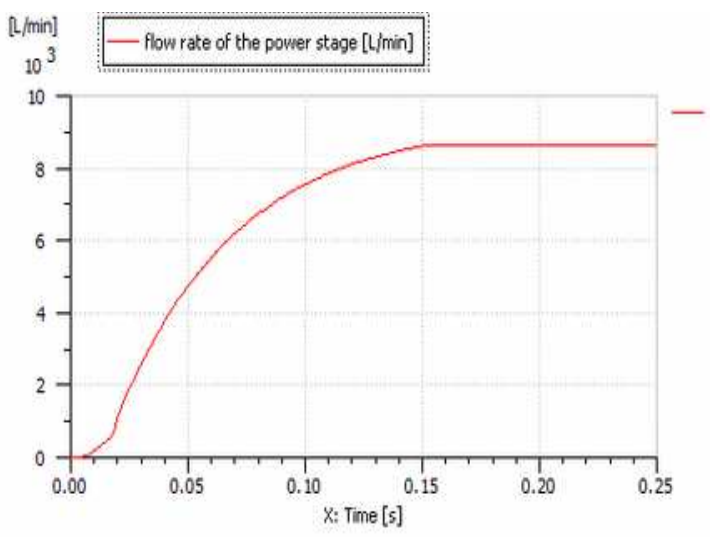

Figure 13. The servo valve flow evolution

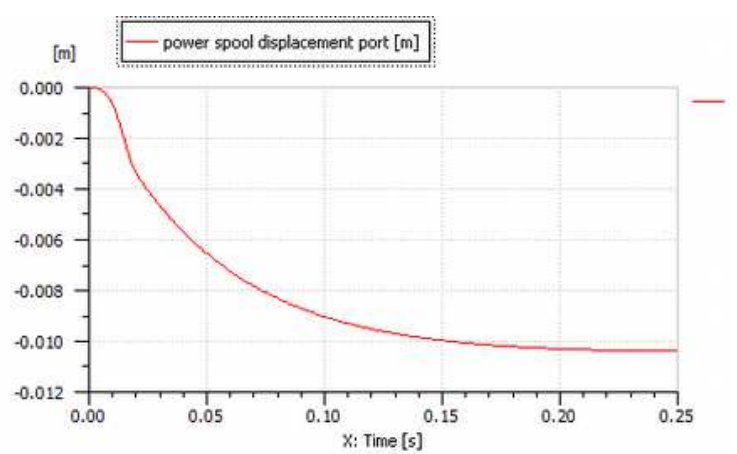

Figure 14. The power stage spool evolution

Second, the authors have simulated a slow linear input signal (Figure 15) in order to find the steadystate characteristics of the valve. The evolution of the main parameters of the system for a typical simulation are presented in Figures 16 - 21.

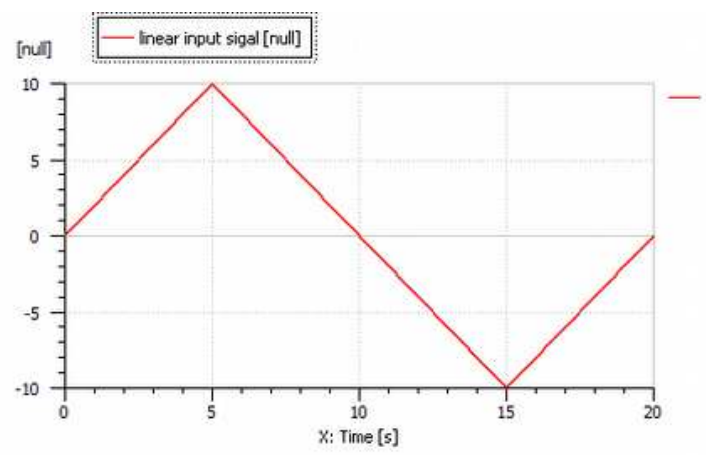

Figure 15. Input voltage applied for finding the steady-state characteristics

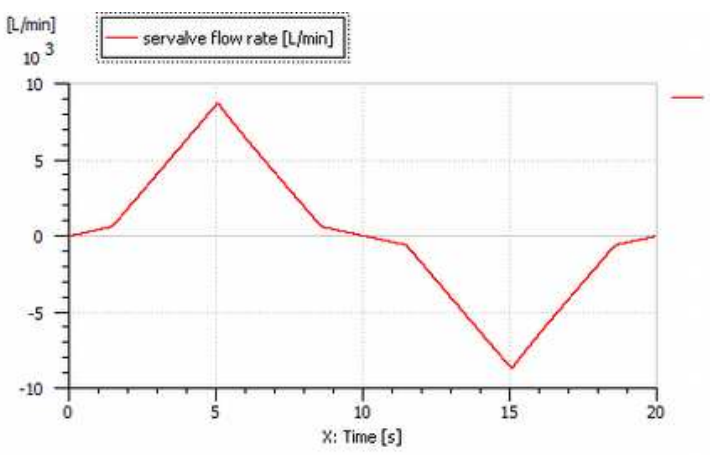

Figure 16. The third stage spool displacement evolution

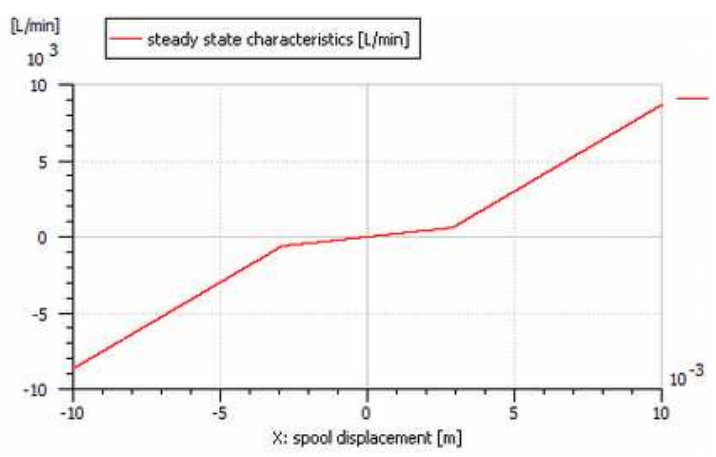

Figure 17. The steady state servo valve characteristics 


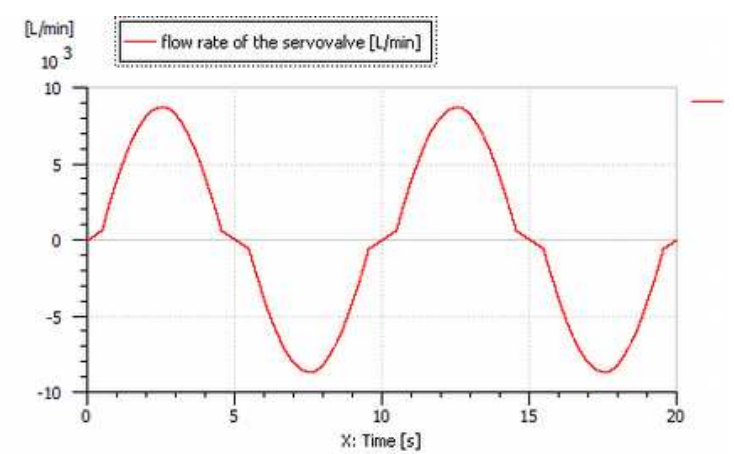

Figure 18. The servo valve flow for a sine input

The numerical simulation show a good dynamic behaviour of the servo valve for different kind of inputs.

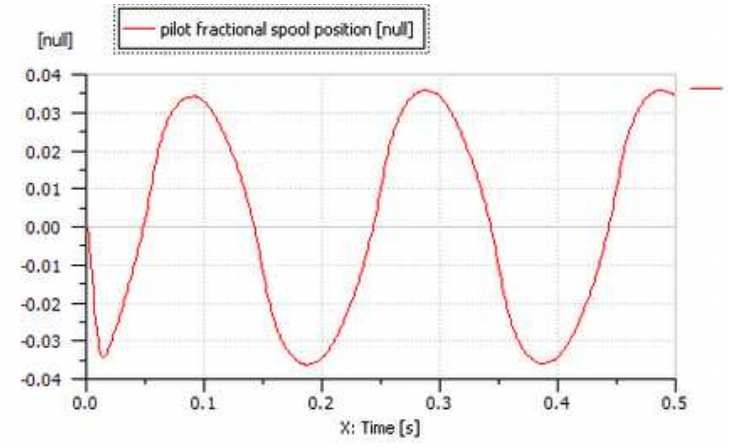

Figure 19. The pilot spool fractional displacement at the beginning of a sine input

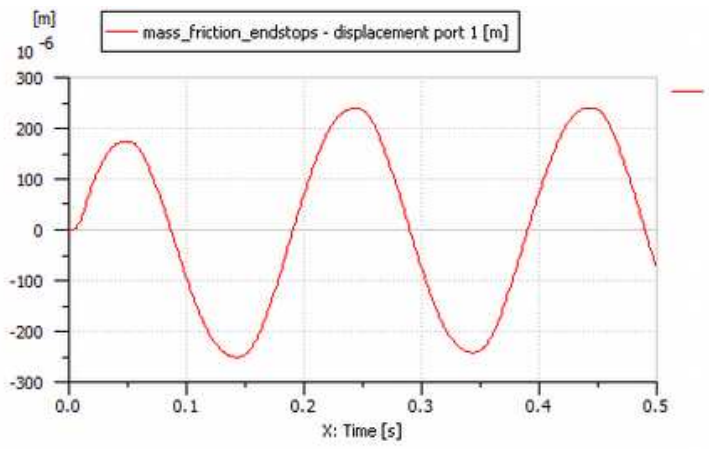

Figure 20. The second stage spool displacement at the beginning of a sine input

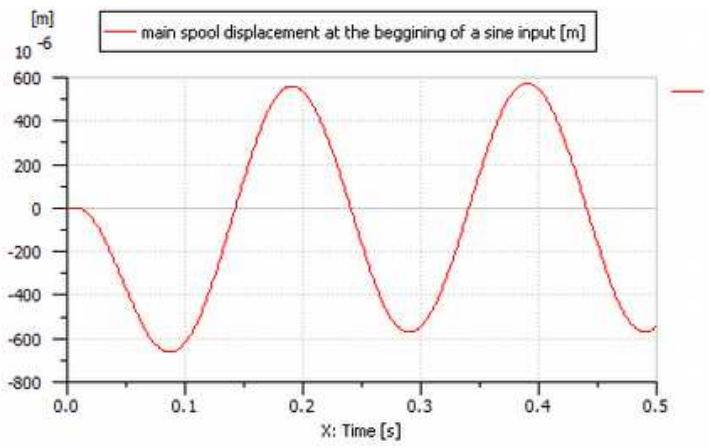

Figure 21. The third stage spool displacement at the beginning of a sine input
The most important quality of this kind of electro-hydraulic converter is the specific behaviour in the null region, and outside this region.

The small slope of the flow curve for small frequency deviations always occurring during the turbine start is very useful for a very quick start of the hydropower unit.

The big slopes allow a quick shutdown ordered by the speed governor or by the overall power station control unit.

\section{Experimental Validation}

The experimental validation of the new design was performed in the fluid power laboratory of the University POLITEHNICA of Bucharest Different types of analogue and digital servo valves were tested in the frame of a servomechanism with strong hydraulic load in order to prepare this subsystem for building a fair model for the whole servo valve assembly.

The results obtained in the previous chapter by numerical simulation have been compared with the experimental data collected by the authors while working on a similar speed governor for the hydropower units of Râmnicu-Vâlcea hydropower plant [1].

Taking into account the high speed response of the REXROTH servo valves [11], used as a preliminary stage in the new three stages design, the dynamic behaviour of the two new governor type is nearly the same.

The only difference comes from the very low pressure supply used for controlling the hydraulic turbine speed with the new three stages servo valve. The speed governors dedicated to entirely new Kaplan turbines are sized for 60 bar, in order to reduce the size of the hydraulic cylinders, and to improve the control system performance.

The authors studied also the level of the safety function of the pilot stage of the new servo valve using a new test bench designed for this purpose (Figure 22). Redundancy problems were solved in order to find the best structure of the controllers, and the architecture of the supervisor controller.

The frequency response of the new type of servo valve was found directly from the AMESIM model, using a special facility of the language (Figure 23). 


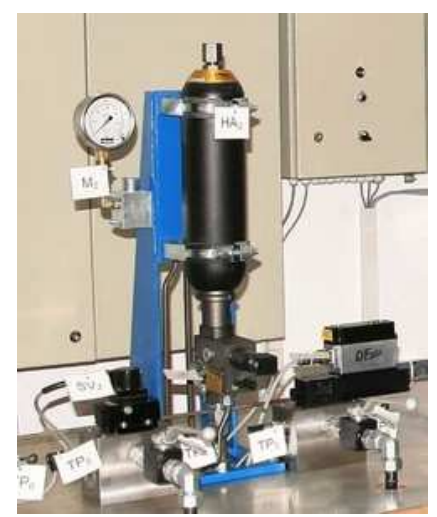

Figure 22. Dynamic test bench for pilot stages

The phase diagram (Figure 24) shows a poor dynamics of the servo valve, due to the very low supply pressure, and the very small slope of the steady state characteristics around the null region. At the same time, the overall behaviour is well suited for the speed control of large hydropower units during start-up.

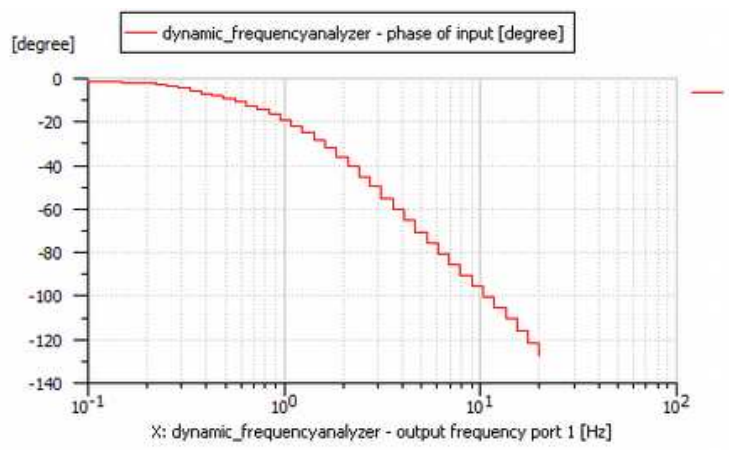

Figure 24. The phase diagram of the servo valve for a small input signal (10\%)

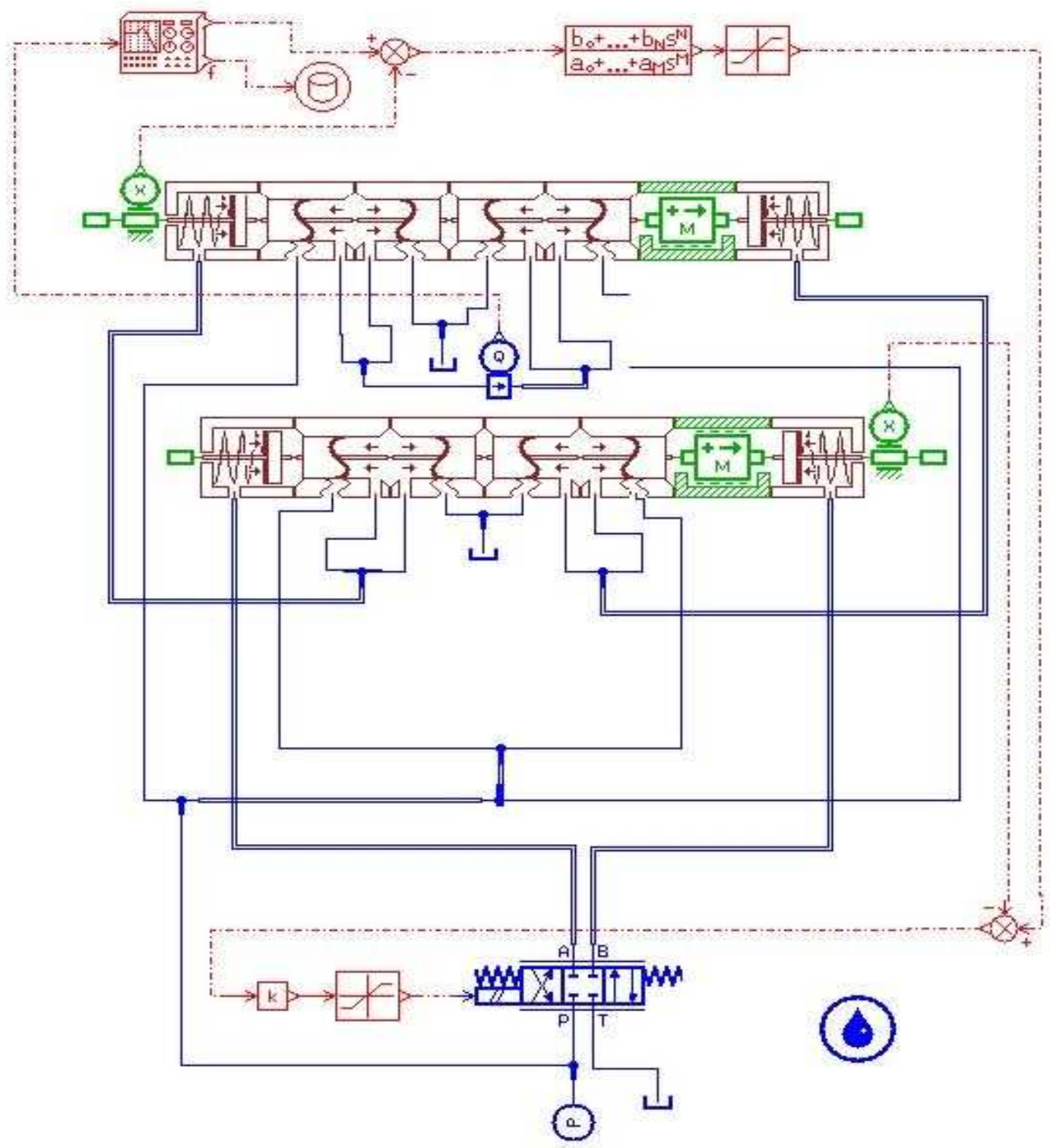

Figure 23. AMESIM model for frequency response computation 


\section{Conclusions}

All the design, test, and identification activities of the new servo valve project pointed out that AMESIM provided a strong solver, and numerical core for transient simulation. As modelling a complex multi-physics system is not the main objective of engineers, it is important to have tools and interfaces, which accelerate and optimize the design. From this point of view, AMESIM is a complete software perfectly adapted for model creation and deployment. The wide field of application, including electric powertrain is continuously extended by the users.

\section{Acknowledgments}

The authors are grateful for all the technical support received from the LMS COMPANY (now a SIEMENS business) in different manners: free licenses, free technical training for the research team members, and many other facilities.

The authors are also grateful to Philippe Geril, the General Secretary of EUROSIS, for the permission of publishing this paper, firstly presented in a short release in the frame of ESM'2015.

The work has been also funded by the Sectoral Operational Program Human Resources Development 2007-2013 of the Ministry of European Funds through the Financial Agreement POSDRU/159/1.5/S/ 132397.

\section{REFERENCES}

1. VASILIU, N., C. CĂLINOIU, Electrohydraulic Digital Speed Governor for Hydropower Units, Romanian Patent no.120101, 2003.

2. CALINOIU, C., G. NEGOIŢĂ, D. VASILIU, N. VASILIU, Simulation as a Tool for Tuning Hydropower Speed Governors, ISC'2011, Venice, Italy.
3. VASILIU, N., C. CALINOIU, D. VASILIU, Modelling, Simulation and Identification of the Electrohydraulic Speed Governors for Kaplan Turbines by AMESIM, Symp. on P. Trans. and Mot. Ctrl., PTMC 2007, UK.

4. MARE, J-C., Modelling of Aerospace Actuation Systems, European AMESIM Conference, Strasbourg, 2006.

5. ROOD, E. O., H. S. CHEN, R. LARSON, F. NPWAK, Development of High Flow, High Performance Hydraulic Servo Valves and Control Methodologies in Support of Future Super Large Scale Skating Table Facilities., 12 WCEE 2000, New Zeeland.

6. LEBRUN, M., D. VASILIU, N. VASILIU, Numerical Simulation of the Fluid Control Systems by AMESIM, Studies in Informatics and Control, 2009, vol. 18(2), p. 111-118.

7. IMAGINE, Numerical Challenges posed by Modelling Hydraulic Systems, Technical Bulletin 114, 2001.

8. LMS, Advanced Modelling and Simulation Environment, Release 13 User Manual, Leuven, 2013.

9. POPESCU, T. C., D. VASILIU, N. VASILIU, Numerical Simulation - a Design Tool for Electro Hydraulic Servo Systems, in "Numerical Simulations, Applications, Examples and Theory", Intech Press, Austria, 2011.

10. COSTIN, I., N. VASILIU, C. CĂLINOIU, D. VASILIU, D. M. BONTOS,, Synthesis of a Three Stages Servo Valve by AMESIM, 29th Euro. Sim. and Modell. Conf. ESM'2015, 2015, UK.

11. *** REXROTH, Servo Solenoid Valves. Technical Specification 13/2, Automation Technology, Stuttgart, 1999. 